\title{
The Efficacy of Virtual Reality-Based Cognitive Training in Older Adults Non-Demented and with Mild Dementia: an One Group Pretest-Posttest Design
}

\section{Ludmiła Zając-Lamparska ( $\square$ lzajac@ukw.edu.pl )}

Kazimierz Wielki University https://orcid.org/0000-0003-4618-547X

Monika Wiłkość-Dębczyńska

Uniwersytet Kazimierza Wielkiego Instytut Psychologii

\section{Adam Wojciechowski}

Politechnika Lodzka

\section{Marta Podhorecka}

Uniwersytet Mikolaja Kopernika Collegium Medicum

\section{Anna Polak-Szabela}

Uniwersytet Mikolaja Kopernika Collegium Medicum

\section{Łukasz Warchoł}

Uniwersytet Kazimierza Wielkiego Instytut Psychologii

\section{Kornelia Kędziora-Kornatowska}

Uniwersytet Mikolaja Kopernika Collegium Medicum

\section{Aleksander Araszkiewicz}

Uniwersytet Mikolaja Kopernika Collegium Medicum

\section{Paweł Izdebski}

Uniwersytet Kazimierza Wielkiego Instytut Psychologii

\section{Research article}

Keywords: Intervention Study, Cognitive Training, Virtual Reality, Cognitive Ageing, Dementia,

Posted Date: July 1st, 2019

DOI: https://doi.org/10.21203/rs.2.10797/v1

License: (c) (i) This work is licensed under a Creative Commons Attribution 4.0 International License. Read Full License 
Version of Record: A version of this preprint was published at BMC Research Notes on November 27th, 2019. See the published version at https://doi.org/10.1186/s13104-019-4810-2. 


\section{Abstract}

Background Current methods of cognitive interventions for older adults are increasingly employing modern technologies. However, research into possible applications of virtual reality (VR) in such interventions has begun only recently. The aim of the study was to evaluate the efficacy of VR-based cognitive training for older adults and to compare this efficacy in older adults without cognitive impairment and with mild dementia. Methods The complete data were obtained from 99 individuals aged 60-89, qualified according to Mini Mental State Examination (MMSE) scores into the group of nondemented older adults ( $n=72$, mean age 68 , MMSE: $28-30)$ or older adults with mild dementia $(n=27$, mean age 72, MMSE: 19-23). An one group pretest-posttest design was applied. Cognitive training with the use of GRADYS software - a computer game with elements of VR was introduced in all participants. The game included four modules corresponding to: attention, memory, visual processing and language. The intervention lasted 4 weeks and consisted of eight sessions, two per week. The intervention program was preceded and followed by a cognitive assessment of processes corresponding to the modules of the game. The following statistical tests were used: the repeated measures multivariate analysis of variance supplemented with one-way tests, the Hotelling T2 test, the Student's t test, the Friedman test, the MannWhitney U test, the Kruskal-Wallis test. Results Both research groups demonstrated progress in the training, which was greater in non-demented older adults for the majority of cognitive modules except for the attention module. There were also significant differences in general cognitive functioning before and after the training. However, positive changes in cognitive performance in particular tests were revealed almost exclusively in the group of older adults without cognitive impairment. There was no relationship between the level achieved in particular training modules and the improvement in corresponding cognitive tasks. Conclusions Currently, we can recommend the GRADS game for use only in nondemented older adults. The hypothesis of the presumable usefulness of the game in individuals with $\mathrm{MCl}$ needs to be tested. In turn, the application of the GRADYS game to people with dementia would require modification of the hardware and software.

\section{Background}

The dynamic development of modern technologies raises questions as to the possibilities, benefits and limitations of their application among the older adults due to the developmental changes in the sensorimotor abilities, cognition and motivation observed in this age group (1). Although seniors proved to be late adapters to the world of modern technologies, the fact remains they effectively use those technologies for their own health protection and promotion, for instance telemedicine, e-health (2).

An important area for modern technologies application in older adults is improving their cognitive functioning through cognitive interventions $(\mathrm{Cl})$, including cognitive training $(\mathrm{CT})$, cognitive stimulation (CS) and cognitive rehabilitation (CR) (3). As people get older, many cognitive abilities deteriorate and the process is referred to as cognitive ageing (4). It mostly affects memory processes, learning, attention, reasoning and executive functions $(5,6,7)$. What is more, the risk of dementia disorders increases with age in the course of various neurodegenerative diseases $(8,9)$. Deterioration in cognitive functioning of 
an older adults results in their reduced independence, lower self-esteem and withdrawal from many areas of activity (professional, social and educational) due to deterioration in mental functions. In view of the above, studies into possible forms of non-pharmaceutical interventions aiming to maintain, improve or enhance cognitive performance, and prevent its deterioration in senior age gain particular relevance.

Research on the methods improving cognitive performance in cognitively healthy older adults and in persons with cognitive impairment, including dementia, have been conducted for many years now and have provided evidence of the effectiveness of various cognitive interventions (10).

For example, the meta-analysis of randomized controlled trials by Chiu and colleagues (11) indicated that CT is effective for non-demented older adults. Similarly, the review of research on CS and CT programs for healthy older participants performed by Tardif and Simard (12) pointed out that the results are promising for memory, attention, executive functions, and speed of processing. Also meta-analyses of the influence of process-based CT, like working memory or cognitive control training, in healthy older adults demonstrated the effectiveness of such $\mathrm{Cl}(13,14)$. Moreover, $\mathrm{CT}$ enhance stability of cognitive functioning across adulthood, as indicated the review by Eschen (15). According to this review all types of CT enhanced absolute stability of cognitive functioning, but the greatest effects were reported for process-based CT. What's more, findings of a few studies discussed in this review demonstrated that thanks to $\mathrm{CT}$ also the absolute stability in brain functioning across adulthood can increase. Also systematic review of randomised controlled trials with longitudinal follow-up revealed that CT can prevent the onset of dementia in healthy older adults (16). CT induced strong and persistent protective effects on longitudinal neuropsychological performance. Some studies considered in this review reported also transfer of training effects to general cognition and daily functioning.

Moreover, $\mathrm{Cl}$ may be beneficial not only in normal ageing process, but also in the case of $\mathrm{MCl}$. The results of all $\mathrm{Cl}$ in cognitively healthy older adults and older adults with $\mathrm{MCl}$ between 1970 and 2007 reviewed by Martin et al. (17) suggest that $\mathrm{Cl}$ lead to performance improvements and that the size of the effects differs for different kinds of memory skills in non-demented older adults and people with mild cognitive impairment (MCl). Systematic review of 10 studies, followed by effect sizes analysis found that CT (including cognitive exercises and memory strategies training) can produce moderate-to-large positive effects on memory-related outcomes in older adults with $\mathrm{MCl}$ (18). Positive influence of $\mathrm{Cl}$, including CT, on various aspects of memory, attention and executive functions in older adults with $\mathrm{MCl}$ was pointed out also in other review (19). Mewborn, Lindbergh and Stephen Miller (20) analysed 279 effects from 97 studies on CT in older adults. Overall, results indicated that CT produce a small, but significant, improvement in the cognitive functioning of older adults, relative to active and passive control groups. At the same time, cognitive status (cognitively healthy vs. $\mathrm{MCl}$ ), as well as age and education were not significant moderators. Effects were larger for directly trained outcomes but were also significant for nontrained outcomes (i.e. transfer effect). However, not all reviews and meta-analyzes on the effects of $\mathrm{Cl}$ in individuals with $\mathrm{MCl}$ lead to such optimistic conclusions. A meta-analysis on memory training effects pointed out the scarce of evidence of the effectiveness and specificity of such CT in older adults without cognitive impairment and with $\mathrm{MCl}(21)$. 
Going further, the results of research on the possibility to improve cognitive functioning under the influence of $\mathrm{Cl}$ in persons with dementia are less clear. Some reviews and meta-analyzes indicated positive effect of $\mathrm{Cl}$ on cognitive functioning in dementia $(22,23,24)$. Based on the analysis of randomized controlled trials, Ballard and colleagues concluded, that modest but significant benefits in the treatment of cognitive symptoms in people with Alzheimer's disease (AD) can be achieved through various $\mathrm{Cl}$, including $\mathrm{CT}, \mathrm{CR}$ and $\mathrm{CS}$ (25). Also the systematic review of the literature and meta-analysis of the effect of $C T$ on multiple functional domains in AD patients showed medium effect sizes for learning, memory, executive functioning, activities of daily living, general cognitive problems, depression, and selfrated general functioning (26). According to the scoping review on the effects of non-pharmacological interventions for adults with mild cognitive impairment and early stage dementia, $\mathrm{Cl}$ focused on remediation caused a little improvement in selected cognitive abilities, in turn cognitive training focused on compensation influenced the impact of cognitive changes impact on daily living (27). The effect sizes were however small. Moreover, most of the studies included in this review concerned $\mathrm{MCl}$ patients. The review comprised 20 studies in persons with $\mathrm{MCl}$, only 8 studies in persons with early $A D$ and 4 studies involved both, $\mathrm{MCl}$ and early $\mathrm{AD}$ patients. Other authors pointed out that convincing evidence of clinical significance for the impact of $\mathrm{Cl}$ in cognitively impaired older adults was only obtained from single trials in terms of delay of cognitive decline, improvement in activities of daily living, or enhanced attainment of personally relevant goals (28). Furthermore, if $\mathrm{Cl}$ types are distinguished, i.e. CT, CS and CR, it turns out that in people with dementia they vary in terms of effectiveness. Meta-analysis and meta-regression by Huntley and colleagues found the significant positive effect of CS on general cognitive functioning in dementia, but no evidence for the positive influence of CT or mixed approach, combining CT and CS (29). Also according to review by Bahar-Fuchs, Clare and Woods (30), CT is not associated with positive or negative effects on cognitive functioning in persons with mild to moderate dementia. In the review on $\mathrm{Cl}$ in cognitively impaiered older adults authors firstly concluded that $\mathrm{Cl}$ improve global cognitive functioning in patients with $\mathrm{MCl}$ or $\mathrm{AD}$ and their abilities of daily living, reduce behavioural disturbances, and have positive effects on quality of life. Secondly, authors noticed the varying effectiveness of particular types of $\mathrm{Cl}$, depending on the level of cognitive deficits. Patients with mild to moderate dementia benefited more from CS, while older adults with $\mathrm{MCl}$ from CT (31). It corresponds to the conclusions from the systematic review of $11 \mathrm{CT}$ studies and 7 CS studies in individuals with dementia (32). In this review evidence for efficiency of CT among demented persons proved to be insufficient and doubtful. Contrary, for CS there was good evidence for general cognitive enhancement, more specifically in language and memory.

Currently, an increasing number of research concerns the efficacy of $\mathrm{Cl}$ using modern technologies, like computerized cognitive training (CCT) or video games (VG). A systematic review on efficacy CCT for cognitively healthy older adult indicated that findings are comparable or better than those from reviews of more traditional, "paper-and-pencil" CT approaches (33). The authors concluded that computerized training may be an effective alternative. Lampit, et al. (34) reviewed the results of fifty-two studies on the effectiveness of CCT encompassing 4,885 healthy older adults. The overall effect size for CCT versus control was small but statistically significant. Small to moderate effect sizes were found for nonverbal 
memory, verbal memory, working memory, processing speed and visuospatial skills. No significant effects were found for executive functions and attention. According to the systematic literature review and metaanalysis by Tetlow and Edwards (35) commercially available CCT can improve cognitive abilities in older adults, who also report improvement on tasks relevant to their everyday lives. Other systematic review on clinical significance of commercially available computerized "brain training" programs was summarized by the authors' conclusion that at least some of such CT software is effective and can supporting healthy ageing (36). Moreover, Edwards et al. (37) conducted a systematic review and meta-analyses of Useful Field of View (UFOV) CT, and their results indicated that UFOV CT enhanced neural outcomes, speed of processing, and attention and showed far transfer to everyday functioning. UFOV CT effects were equivalent when compared to active- or no-contact control conditions. Moreover, improvements on the trained skills endured across ten years. Admittedly, they did not transfer to other neuropsychological outcomes, however positively enhanced well-being, health, and quality of life. A systematic review and meta-analysis on computer-based $\mathrm{Cl}$ for people with dementia proved that these $\mathrm{Cl}$ have moderate effects in cognition and mood but not on activities of daily living (38). A PRISMA-compliant network metaanalysis led to conclusion that in older adults with $\mathrm{MCl}$ and $\mathrm{AD}$ optimal intervention for cognitive performance is physical exercise, whereas CCT is the optimum for neuropsychiatric symptoms (39). This meta-analysis also showed that nonpharmacological therapies are better than pharmacological therapies in $\mathrm{MCl}$ and $\mathrm{AD}$ patients. Another meta-analysis concerned the efficacy of CCT in people with $\mathrm{MCl}$ or dementia indicated moderate overall effect on cognition in $\mathrm{MCl}$ and small to moderate effects for global cognition, attention, working memory, learning, and memory, with the exception of nonverbal memory (40). In turn in dementia, statistically significant effects were found on overall cognition and visuospatial skills, but the last ones were driven by trials of VR or VG. The authors concluded that CCT is efficacious in people with $\mathrm{MCl}$ but evidence for efficacy in people with dementia is weak and limited to trials of immersive technologies. The newest scoping review on non-immersive brain gaming for cognitively impaired older adults showed that most brain gaming interventions with the use of computer and/or touch screen led to improvement in at least one cognitive outcome (41). Going further, according to this review in older adults with $\mathrm{MCl}$ it was possible to get the near transfer effect by training in processing speed, memory, attention, and working memory, the far transfer effect by training in attention and working memory, and improvement in functional activities by training in visual processing speed and attention, or working memory. In turn, in older adults with dementia the supervised brain gaming training in memory, executive function, and language led to the near transfer effect. The conclusion of the authors points to the potential of brain gaming in the improvement of cognitive functioning in older adults with mild to severe cognitive decline. As regards VG, from a meta-analytic study on the enhancement of cognitive functioning in healthy older adults under influence of VG-based CT followed that such training induces positive changes in reaction time, attention, memory, and global cognition (42). The research by Wang, Zhu, Qi, Huang, and Li (43) proved that VG experiences may have a positive influence also on the brain activation underlying cognitive performance. Their results showed that healthy older VG players presented significantly better cognitive performance than non-VG players and greater brain activity, mainly in frontal-parietal areas. 
Along with the intensive development of modern technologies, more and more advanced solutions are becoming available. In this context the use of VR in the $\mathrm{Cl}$ is a new research area arousing growing interest. VR can be defined as "an advanced form of human-computer interface that allows the user to interact with and become immersed in a computer-generated environment in a naturalistic fashion" (44, p. 298). Currently the standard for fully immersive VR are head-mounted displays (HMDs) because they provide the greatest level of immersion. Besides HMD, VR can be implemented by world-fixed displays taking many forms, from a standard monitor to displays completely surrounding the user e.g., CAVEs, and hand-held displays, like smartphones or tablets $(45,46)$. Evidence is accumulating showing that VRapplications can successfully be employed for early detection and monitoring of physical and cognitive impairment $(47,48,49,50)$, but also for interventions in a wide range of medical conditions, like chronic pain, obesity, eating disorders, anxiety, phobia, depression, schizophrenia, autism, behavioural disorders and cognitive disorders of various etiologies $(51,52,53,54,55,56,57)$.

One major benefit of VR-based CT is that it addresses previous criticisms about CCT by providing individuals with an intervention that is immersive, naturalistic, and mimics real-time and real-life, increasing ecologic validity $(54,58,59,60)$. Ecological validity provided by VR can be seen as a key component for assessing and training cognitive skills that are relevant for functional tasks in real-world contexts $(61,62,63)$.

Moreover, it is worth to be noted that VR applications like VG and CCT create favourable conditions to implement the rules of so called serious games in CT for older adults $(64,65)$. Serious games have been used in the field of neurodegenerative disorders such as Alzheimer's disease to support and improve the assessment of different functional and cognitive abilities, and to provide alternative solutions for patients' rehabilitation. Results confirmed that SG are also adapted to older people with $\mathrm{MCl}(66)$.

In summary, currently VR technology is considered as one of the most promising tools for providing nonpharmacological cognitive interventions for cognitively healthy older adults and persons with different level of cognitive impairment $(54,67)$.

Nevertheless, research on the effectiveness of VR-based CT is still scarce, all the more so in the group of older adults and in relation to cognitive ageing. For example in the systematic review of VR applications in inpatient medical settings between 2005 and 2015, only one of 11 studies included in the review concerned cognitive rehabilitation. This study was however not focused on cognitive ageing. It involved 18 patients with traumatic brain injury, aged 19-73 years (51).

The efficacy of CCT and VR-based CT in older adults with $\mathrm{MCl}$ or dementia was assessed in systematic review by Coyle, Traynor and Solowij (68). The cognitive domains of attention, executive function, and memory (visual and verbal) showed the most consistent improvements, including long-term effects. CCT and VR-based CT were however moderately effective in long-term improvement of cognition for those at high risk of cognitive decline and did not improve the activity of daily living. It should be noted that only three studies using VR-based CT were taken into account in the systematic review, although the authors 
pointed out that the review was undertaken following a wide search of the available literature on the topic area. It indicates the small number of studies carried out so far on this topic.

Recently, several studies have been published, the results of which are generally promising. However, the study samples are usually small, including case studies and articles describe pilot studies or even the research plan with only partial results from initial phases of the study which are continued $(61,69,70$, 71). It is recommended that research into possible applications of VR in $\mathrm{Cl}$ shall be conducted because of the preliminary nature of most data currently available in this area and a relatively small number of studies carried out so far $(54,68)$.

\section{Methods}

\section{The aims and study design}

The aim of the study was to evaluate the efficacy of the VR-based cognitive training in persons aged 60 and above without cognitive impairment and with mild dementia.

In our research we have posed the following hypotheses:

1. In the process of training using GRADYS game an improvement in the performance of the training tasks will occur, manifested in reaching higher levels of the game difficulty in each of the training modules, regarding: memory, attention, language, visual processing.

2. The effect of the training will result in an improvement in cognitive performance beyond the game environment, i.e. in the performance of standard cognitive measures of memory, attention, language and visuospatial processing.

3. Belonging to the group of older adults without cognitive impairment vs. older adults with mild dementia will differentiate the participants in terms of cognitive performance in pretest and in terms of training effects. The cognitive performance in pretest will be better in non-demented older adults compared to participants with mild dementia. Training effects in both groups will be significant and positive, as described in hypotheses 1 and 2, but in the group of non-demented older adults they will be greater.

4. There will be a positive relationship between the progression in the training and the improvement of cognitive performance beyond the game environment, i.e. participants with greater achievements in training will demonstrate a greater improvement in cognitive performance beyond the game environment.

An uncontrolled pretest-posttest study design was applied. The GRADYS game was tested through training organized for the study participants. The training was preceded and followed by the cognitive functioning measurement.

The subjects from both study groups participated in eight training sessions, two per each week. Each session provided training with two software modules aimed to stimulate different cognitive 
functions in the following pairs: (a) memory and attention; (b) language and visuospatial processing. As a result, each module involved four training sessions. A single session lasted 45 minutes to one hour, depending on the pace of work of individual participants. In every training session subjects were accompanied by a training assistant - a trained person who provided explanations or guidance if necessary.

For each cognitive function, the study participants started the first session at the first, lowest difficulty level. The highest possible difficulty level to achieve was level 3 . The participant moved to a higher level having reached $75 \%$ accuracy in the previous training session. In the case of accuracy falling below $50 \%$, the participant returned to the lower level of the game.

Before starting the training programme and after its completion, the study participants' cognitive functioning was evaluated.

\section{Participants}

The study was conducted in Poland. All participants were Polish citizens for whom Polish was a native language. The initial study sample consisted of 150 individuals, including 75 patients with mild dementia (Mini Mental State Examination: 19 - 23 points) aged 60-89 recruited from patients of a geriatric clinic, from patients of a healthcare facility of the „Nowa Wspolna Droga” Association in Gniezno and through advertisement, and 75 volunteers aged 60-88 without cognitive impairments (Mini Mental State Examination: 28 - 30 points) recruited through advertisement. The inclusion criteria for the sample also included a lack of mental disorders and serious somatic illnesses, as well as visual, auditory and motor impairments preventing the use of the game peripherals. All subjects signed informed consent forms to participate in the study. In the case of individuals with cognitive impairment consent was also obtained from their actual caregivers. The data from two measurements collected prior to the training and after the training were obtained from 27 older adults with mild dementia and 72 non-demented older adults. Those individuals were included in the final sample described below in Table 2. A significant loss from the group of subjects with mild dementia resulted from difficulties faced during training, their need to be accompanied by caregivers who often showed lack of time and tiredness of study procedure leading to its discontinuation.

The study was conducted in the Institute of Psychology at the Kazimierz Wielki University in Bydgoszcz, and in the Departments of Geriatrics and Psychiatry at the Nicolaus Copernicus University in Torun, Collegium Medicum in Bydgoszcz as well as in a healthcare facility of the "Nowa Wspolna Droga” Association in Gniezno.

\section{Intervention}

The work on the development of the GRADYS game can be described based on the scheme of technology development and evaluation process (1). This scheme describes a sequence of activities that 
starts with the research on the needs assessment of the intended users of a given technology, and continues in two phases, the lab phase and the field phase.

The starting point for the work on the GRADYS game was to identify the needs of the end user and the nature of $\mathrm{CT}$ to be implemented in the game. The above-mentioned cognitive decline observed in the ageing process, supported by numerous research findings, provides objective evidence that CT is a significant and positive intervention targeted at older adults. Based on the current literature on cognitive ageing the game was decided to engage four main cognitive functions: two that show pronounced deterioration with age even in the absence of dementia (and in the case of dementia even more pronounced), i.e. memory and attention, and two that deteriorate less seriously in normal ageing but significantly in the course of dementia, namely language and visual-spatial function.

The perceived need in older adults to improve their cognitive function was confirmed in meetings with people from this age group, at Universities of the Third Age among others and at various institutions for seniors. Given the characteristics of the target group, the tasks for the game then developed were to simulate cognitive functions while maintaining the users' physical comfort and mental welfare as well as their interest and motivation to use the game. In order to realize those tasks, it was assumed that GRADYS shall meet the following criteria.

- The exercises that engage cognitive functions shall be embedded in the context of real-life places, situations and every-day activities of seniors living in Poland for the scenario to be perceived as natural and familiar to the user.

- The game environment shall reflect the natural environment, yet it shall not be too rich as not to provide undue stimulation that is beyond the attention and perception capacity of the end user.

- The game shall enable the user to play at increasingly higher and more difficult levels and the players shall be informed about their results and progress made in the game to induce and maintain their motivation to play the game.

- The game shall be played while seated to ensure the user's physical comfort and safety since VR setting prevents visual control of the surroundings.

- It is necessary for a simultaneous use of game devices, including VR and standard visual and auditory correction devices that are often indispensable for older adults.

- The VR devices shall be relatively easy to use so that they do not pose an additional challenge for or build resistance and fear in the end users.

- The users shall be able to play the game on their own without the assistance of an instructor or any trained person for the end product to be used by older adults in their homes.

- The game as a whole (both software and hardware) shall use such solutions that will make the end product affordable for institutions working with seniors in Poland, and possibly - also for individual users, being private persons. 
The subsequent phases of game development in the context of the concerned scheme of technology development and evaluation process involved laboratory work and have been described in Table 2.

The final result of laboratory work was the GRADYS game which is a CT with VR elements for cognitive enhancement in older adults. The efficacy of this game as a CT was tested in the research.

There are four modules in the game dedicated to the four areas of cognitive functioning: (1) attention; (2) memory; (3) language; (4) visuospatial processing. The storyline of each module scenario consists in several tasks that create a consistent story line inspired by daily life events. For every cognitive module there are two possible scenarios, of which one is set at home and the other takes place outside the home environment. There are three difficulty levels for each module and location. The game software also includes a tutorial that helps users learn the ways to navigate the game and allows them to practice.

The player moves in the game environment and interacts with it from the first-person perspective (FPP). The game is controlled with the Oculus Rift DK2 and the Xbox 6DOF control pad. For detailed characteristics of the GRADYS game see different article (72).

\section{Outcome measures}

Two sets of research tools were used: screening tests that help select subjects for the study sample and tools that evaluate cognitive functioning before starting the training with the GRADYS game (pretest) and following its completion (posttest).

The following research tools were used in the study:

1. Screening tests:

- Structured interview - for the assessment of inclusion criteria and sociodemographic variables;

- Mini Mental State Examination (MMSE) - for the classifications to two research groups: nondemented older adults and older adults with mild dementia, according to the cognitive functioning;

- Addenbrooke Cognitive Examination III (ACE - III) - for the assessment of cognitive functioning in addition to MMSE.

1. Tools to measure cognitive abilities according to four modules (pretest and posttest):

- Module 1. Memory: Digit Span test contained in WAIS - R (PL), Benton Visual Retention Test (BVRT), Rey Auditory Verbal Learning Test (AVLT), Famous Faces Test, Rey-Osterrieth complex figure test (ROCF) - delayed reproduction;

- Module 2. Attention: Digit Symbol test contained in WAIS - R (PL); Colour trial test (CTT) - Adult version, d2 Test of Attention (including following performance indices: WZ - speed of processing, $\% B$ - percentage of errors, WZ-B - error corrected speed of processing, ZK - ability to concentrate); 
- Module 3. Visuospatial abilities: a block design test contained in WAIS - R (PL), Rey-Osterrieth complex figure test (ROCF) - direct copying.

- Module 4. Language abilities: Verbal fluency test (from ACE - III); Boston Naming Test (BNT);

\section{Data analysis}

The comparison of baseline cognitive performance in non-demented older adults and older adults with mild dementia was made using the Hotelling $T^{2}$ test - for cognitive performance in general and the Student's $t$ test - for the results of particular cognitive measures. In the case that homogeneity of variance was violated, the Welch's $t$ test was used. The $t$ test was also supplemented by the nonparametric Mann-Whitney $U$ test due to unequal number of participants in both groups.

In order to evaluate the progress made by the subjects throughout the training, we compared difficulty levels reached by the subjects in each module separately within each group: older adults without cognitive impairment and older adults with mild dementia. For this purpose, with regard to the ordinal character of the dependent variable, the non-parametric Friedman test was used. Inter-group comparisons of the training progress was carried out for the last, fourth session within each cognitive module with the use of the Mann-Whitney U test.

The evaluation of change in each cognitive ability that occurred due to training measured by means of other than training-related tasks, including a comparison between the study groups of nondemented older adults and older adults with mild dementia was carried out with the use of the repeated measures multivariate analysis of variance (RM MANOVA) with group as a between-subject variable. Due to disproportion in the sizes of both groups, RM MANOVA was conducted also in the two groups separately. RM MANOVA in both groups was supplemented by one-way tests for particular outcome measures.

Finally, to compare participants who achieved different levels of difficulty at the end of the training in terms of the changes of cognitive tests performance the Kruskal-Wallis test or the Mann-Whitney $U$ test were used (depending on the number of groups being compared) separately in both groups. All statistical analyses were conducted in Statistica 13.

\section{Results}

Baseline cognitive performance. As expected, statistical analyses indicated better baseline cognitive performance in the group of non-demented older adults in general (Hotelling $T^{2}=130.868 ; p<.001$ ) and in the majority of pretest cognitive measures (Table 3). In a few of cognitive measures, there was no significant differences between groups (Table 3). All these cognitive measures was relatively easy. Surprisingly, two performance indices in the sustained attention task (d2) were significantly better in the group of older adults with dementia in comparison to participants without cognitive impairment (Table 3). However, the WZ-B indicator is vulnerable to overestimation due to the skipping a part of the characters in the row. Therefore, the high WZ indicator can be an artefact resulting from the fact that 
participants with mild dementia often acted contrary to instructions of $d 2$ test to follow the letters in a row one by one and moved immediately to further letters. The value of the next indicator higher in the group with dementia, i.e. WZ-B, can be a derivative of WZ value.

The progress throughout the training. Both groups demonstrated progress throughout the training: older adults without cognitive impairment and older adults with mild dementia (Table 4, the Friedman's test; Figure 2). Yet the group of non-demented older adults showed greater progress for the majority of cognitive modules except the attention module, in which the difference between the groups in the last training session was not statistically significant (Table 4, the Mann-Whitney $U$ test). At the same time, the mean and the median values of the difficulty levels achieved by the participants in consecutive training sessions, as well as the percentage of participants who achieved particular levels of difficulty in subsequent sessions of a given module indicated uneven difficulty of the cognitive modules. The memory module was found to be most difficult for the study participants, while the attention module was the easiest one.

\section{Changes in cognitive functioning under the influence of training with the GRADYS game. RM MANOVA} with group as a between-subject variable showed two significant effects (Table 5). Firstly, the groups of older adults without cognitive impairment and older adults with mild dementia differed significantly as regards the level of cognitive functioning. Secondly, there was also significant differences in cognitive functioning before the training with the use of the GRADYS game and after its completion.

As regards the interaction effect, it is not significant yet the probability value $(p=.073)$ was only slightly above the assumed value of statistical significance with $a=.05$. While partial eta squared for the interaction effect was 0.348 which means a large effect size (73). This finding is sufficient to justify further analysis that help to isolate exactly where are the significant means differences. Obtained effect size suggested that the group may be a factor moderating the effect of training with regard at least to a part of applied measures of cognitive abilities.

According to RM MANOVA computed for each group separately, significant changes occurred only in older adults without cognitive impairment (Table 6). However, in the group of older adults with mild dementia the observed power was low, in turn the effect size was big. It suggest that the statistical power of conducted test was insufficient to estimate the cognitive changes after the training in the population of older adults with mild dementia. The reason probably was, at least partially, too small sample size and high sampling error. 
In turn, one-way tests for the differences between pretest and posttest for particular cognitive measures computed in both groups indicated some significant changes in the group of older adults with mild dementia, however much less than in the group of non-demented participants (Table 7). Cognitive domains for which the improvement proved to be most pronounced were attention and visuospatial processing.

With regard to attention, its measures improved after the training mainly in the group older adults without cognitive impairment. This applied to all $\mathrm{d} 2$ test's indicators and to the shortening of the time of CTT-2 test performance. Whereas in the group of older adults with mild dementia, post-training significant changes revealed only in one indicator from a fairly easy $d 2$ test. The percentage of errors in $d 2$ test decreased significantly.

Among the visuospatial measures in non-demented older adults, the performance of Block Design from WAIS - R (PL) improved significantly, while the correctness of the direct ROCF copy improved in older adults with mild dementia. It can be noted that after training, the cognitively not impaired participants improved performance of more demanding cognitive tasks, while individuals with mild dementia - of the easier ones.

Regarding memory, improvement was noted only in three indicators and only in the group of older adults without cognitive impairment. These indicators were: backward Digit span from WAIS - R (PL), delayed recall of ROCF and error indicator from BVRT. In turn, the indicator of correct responses in BVRT has deteriorated in persons with mild dementia.

There was no improvement in performance on the measures of language abilities - the verbal fluency test or the Boston Naming Test.

\section{The relationship between the progression in the training and the improvement of cognitive performance} beyond the game environment. The comparison between participants who differ in final levels of difficulty achieved in particular game modules indicated no relationship between the training progress in a given cognitive module and improvement in cognitive functioning corresponding to it (Tables 8 and 9). These comparisons were conducted separately in non-demented older adults and older adults with mild dementia. In some cases, three groups were compared, corresponding to three levels of difficulty that could be achieved in the last training session (Table 8). Ultimately, in some cases only two groups were compared, as in cases where very few participants remained at the lowest level of difficulty at the end of the training (level 1), this subgroup was combined with participants that have reached level 2 (Table 9). This was only the case for the older adults without cognitive impairment. No comparison of the training achievements in the attention module was made because almost all participants finished this module at the maximum difficulty level. It was 67 participants form a 72-strong group of non-demented older adults (96\%) and 23 participants from a group of 27 older adults with mild dementia (85\%).

\section{Discussion}


The aim of the research discussed in the present paper was to evaluate the efficacy of the cognitive training using the game with elements of VR in the target group of people aged 60 and above without cognitive impairments and with mild dementia.

The study leads to the general conclusion that the GRADYS game can be used by non-demented older adults. Whereas the usefulness of the GRADYS game for people with mild dementia is questionable and at this point we cannot recommend our software for this group.

Participants with mild dementia before the start of the training were worse in cognitive tasks than nondemented older adults, which is a rather obvious result. Nevertheless, subjects from both groups showed progress in the course of training within all cognitive modules included in the software. The progress was indicated by increasingly higher difficulty levels reached by the players in subsequent training sessions. One can therefore conclude that the proposed solution is learnable and effective when it comes to improving on the performance of the trained cognitive tasks for all participants of the study. However, among older adults with mild dementia not only less progress in the training, but also a large loss of participants from the sample was observed. Many subjects from the group of adults with mild dementia selected for the study withdrew from participation during the training process, some of them in view of major difficulties involved in its completion, including difficulties involved in controlling the game and inability to concentrate on cognitive tasks due to an excessive cognitive burden in using new technology (getting their bearings in VR, using controllers). In those cases, low learnability caused lack of acceptability of the GRADYS game, which in turn contributes to decreased efficiency of this game in older adults with mild dementia.

As regards effectiveness in enhancing cognitive functions beyond the tasks trained in the game environment (i.e. transfer), a significant difference in cognitive tests performance before and after training indicated in RM MANOVA proves a positive impact of the training. At the same time, one-way tests computed for particular outcome measures separately in both groups revealed that positive changes in the performance of cognitive tasks are observed almost exclusively in non-demented older adults.

In the case of older adults without cognitive impairments, we can speak about overall enhancement of attention indicators. In this group also improved: visuospatial processing (although only two its indicators were taken into account in the study), visual aspects of memory and working memory, but not verbal learning and language.

The situation is quite different among older adults with mild dementia. Positive changes in this group are observed only in the percentage of errors in $\mathrm{d} 2$ test and in the copy of Rey-Osterrieth complex figure which belong to the easiest tasks in the whole set of cognitive measures used in this research. Moreover, in this group in the assessment after training increases the number of errors in BVRT. 
Poor training effects in participants with mild dementia, despite its higher effectiveness in non-demented older adults are consistent with the results of previous studies, which prove that in individuals with dementia CS or perhaps CR work better than CT $(22,25,29,30,31,32)$. At the same time, research shows that in the case of $\mathrm{MCl}$, the situation is reversed and CT is more effective than CS (31). Moreover, in persons with $\mathrm{MCI}$ CT leads to better effects than in those with dementia (40) and can even retain the effectiveness comparable to those observed in older adults without cognitive impairment (20). Since the CT using GRADYS game showed sufficient learnability for non-demented older adults and some older adults with mild dementia, it can be assumed that it may also be used by individuals with $\mathrm{MCl}$. This hypothesis would require an empirical verification, however, the results of previous research encourage testing the effectiveness of the GRADYS game in $\mathrm{MCl}$ patients.

Other conclusion regards possibilities to enhance the game through making the game control more natural and easier by, for example, replacing the control pad with a haptic glove for VR. Thanks to such improvements the game may become useful also for older adults with mild dementia.

Finally, in the light of the research results, changes in the performance of cognitive tasks beyond the game environment are not related to the results of the training itself, contrary to what was expected. Although significant changes after the training occurred only in some outcome cognitive measures, what made difficult to observe their relation with the progress in training, however even statistical significant improvement in cognitive tests was not associated with the progress in training modules. It should be noted that it is still do not known what is the mechanism underlying such hypothetical relationship would it be the progress level or pace or difficulty level of tasks. Perhaps it is also possible to improve cognitive functioning regardless of the progress in training, as a consequence of cognitive activation itself. This would require further investigation.

Our study bears several shortcomings which may give directions for further studies. First of all, an quasi-experimental uncontrolled pretest-posttest design was applied. The lack of a control group makes it impossible to differentiate the training-related effect from the effect of repeated measurement and practice effect. Simultaneously, in order to reduce the probability of the practice effect occurrence for the majority of cognitive measures applied in pretest and posttest, different versions of the test were used (except for those, where no such versions exist). In addition, because the improvement occurred for some cognitive measures using different versions in the pretest and posttest, and at the same time the improvement did not occur for some measures using the same versions in the pretest and posttest, the observed improvement cannot be attributed to the simple practice effect. However, further development of the GRADYS game will definitely require conducting a study on its effectiveness in enhancing cognitive functions of older adults, including control groups - a passive and active one.

The shortcoming of our research was also design a game control system too difficult for participants with mild dementia causing them to withdraw from training.

The limitations also include the unequal number of neuropsychological measures of particular cognitive functions with fewer indicators for language and visuospatial functions.

Page 16/36 


\section{Conclusions}

The GRADYS game can be useful in cognitive training in non-demented older adults. The hypothesis that it can also be used in older adults with $\mathrm{MCl}$ needs to be tested. Currently, we cannot recommend the GRADYS game for use in persons with dementia, but maybe it will be possible after the adaptation of software and hardware of the game. The rapid development of modern technologies creates opportunities for improving current conceptual solutions, software and hardware with regard to the game natural feel, intuitive simplicity and comfort, as well as its affordability for institutions working with seniors and individual users.

\section{Abbreviations}

ACE-III - Addenbrooke Cognitive Examination III

$A D$ - Alzheimer's disease

AVLT - Rey Auditory Verbal Learning Test

BVRT - Benton Visual Retention Test

CCT - computerized cognitive training

$\mathrm{Cl}$ - cognitive interventions

CR - cognitive rehabilitation

CS - cognitive stimulation

CT - cognitive training

CTT - Colour trial test

FPP - first-person perspective

HMD - head-mounted display

$\mathrm{MCl}$ - mild cognitive impairment

MMSE - Mini Mental State Examination

RM MANOVA - repeated measures multivariate analysis of variance

ROCF - Rey-Osterrieth complex figure test

UFOV - Useful Field of View 
VG - video games

VR - virtual reality

WAIS - R (PL) - Wechsler Adult Intelligence Scale - Revised (Polish)

\section{Declarations}

\section{Ethics approval and consent to participate}

All procedures performed in studies involving human participants were in accordance with the ethical standards of the institutional and/or national research committee and with the 1964 Helsinki declaration and its later amendments or comparable ethical standards. The study protocol and the informed consent form was approved by the Bioethics Committee of the Nicolaus Copernicus University in Torun functioning at Collegium Medicum in Bydgoszcz which acts pursuant to the regulation of the Minister of Health and Welfare of May 11, 1999 on detailed rules for the creation, financing and functioning of bioethics committees (Dz. U. [Journal of Laws] No 47, item 480).

Informed consent was obtained from all individual participants included in the study. All subjects gave written informed consent in accordance with the Declaration of Helsinki. If the participants with mild dementia had a legal guardian, the legal guardian gave written informed consent in accordance with the Declaration of Helsinki.

This article does not contain any studies with animals performed by any of the authors.

\section{Consent for publication}

Not applicable.

\section{Availability of data and materials}

The datasets used and/or analysed during the current study are available from the corresponding author on reasonable request.

\section{Competing interests}

The authors declare that they have no competing interests.

\section{Funding}

This study was funded by the National Centre for Research and Development, Poland (Grant No. IS1/004/NCBR/2014). The funding body did not play any role in the design of the study and collection, analysis, and interpretation of data and in writing the manuscript.

\section{Authors' contributions}


LZL, MWD and PI contributed conception and design of the study; AW designed the technological aspects of GRADYS game and supervised the software development; LZL organized the database; LZL performed the statistical analysis; LZL, MWD and PI interpreted the results of statistical analysis; LZL wrote the first draft of the manuscript; LZL, MWD and PI wrote sections of the manuscript. KKK and AA coordinated and supervised data acquisition in patients with mild dementia. LZL, MWD and PI coordinated and supervised data acquisition in healthy older adults. MP, APS, $Ł W, L Z L$ and MWD contributed data acquisition. All authors contributed to manuscript revision, read and approved the submitted version.

\section{Acknowledgements}

We would like to thank all co-authors of the game scenarios: Paulina Andryszak, Anna Dudzic-Koc, Kamila Litwic-Kamińska, Agnieszka Szałkowska and game programmers: Adrian Fijałkowski, Tomasz Gałaj, Sławomir Opałka, Magdalena Rawicka.

The study was carried out by a consortium composed of the Institute of Psychology, Kazimierz Wielki University in Bydgoszcz, Poland; the Department of Geriatrics, Nicolaus Copernicus University in Torun, Collegium Medicum in Bydgoszcz, Poland; the Department of Psychiatry, Nicolaus Copernicus University in Toruń, Collegium Medicum in Bydgoszcz, Poland; the „Nowa Wspólna Droga” Association; PB Online Sp. z 0.o.; Wyższa Szkoła Technologii Informatycznych w Warszawie (ang. The University of Information Technology in Warsaw).

\section{References}

1. Schulz R, Wahl HW, Matthews JT, De Vito Dabbs A, Beach SR, Czaja SJ. Advancing the aging and technology agenda in gerontology. Gerontologist. 2015;55(5):724-34.

2. Smith A. Older Adults and Technology Use. Pew Res Cent. 2014;April:1-26.

3. Alves J, Magalhães R, Machado Á, Gonçalves ÓF, Sampaio A, Petrosyan A. Non-pharmacological cognitive intervention for aging and dementia: Current perspectives. World $\mathrm{J}$ Clin Cases. 2013;1(8):233.

4. Harada CN, Love MCN, Triebel K. Normal Cognitive Aging. Clin Geriatr Med. 2013;29(4):737-52.

5. Park DC, Lautenschlager G, Hedden T, Davidson NS, Smith AD, Smith PK. Models of visuospatial and verbal memory across the adult life span. Psychol Aging. 2002;17(2):299-320.

6. Salthouse TA. What and When of Cognitive Aging. Curr Dir Psychol Sci [Internet]. 2004;13(4):140-4.

7. Murman DL. The Impact of Age on Cognition. Semin Hear. 2015; 36(3):111-21.

8. Hugo J, Ganguli M. Dementia and Cognitive Impairment: Epidemiology, Diagnosis, and Treatment. Clin Geriatr Med. 2014;30(3):421-42.

9. McKhann GM, Knopman DS, Chertkow H, Hyman BT, Jack CR, Kawas CH, et al. The diagnosis of dementia due to Alzheimer's disease: Recommendations from the National Institute on AgingAlzheimer's Association workgroups on diagnostic guidelines for Alzheimer's disease. Alzheimer's Dement. 2011;7(3):263-9. 
10. Stine-Morrow EAL, Basak C. Cognitive Interventions. In: Handbook of the Psychology of Aging. Elsevier; 2011. p. 153-71.

11. Chiu H-L, Chu H, Tsai J-C, Liu D, Chen Y-R, Yang H-L, et al. The effect of cognitive-based training for the healthy older people: A meta-analysis of randomized controlled trials. PLoS One. 2017;12(5):e0176742.

12. Tardif S, Simard M. Cognitive Stimulation Programs in Healthy Elderly: A Review. Int J Alzheimers Dis. 2011; doi:10.4061/2011/378934

13. Karbach J, Verhaeghen P. Making Working Memory Work: A Meta-Analysis of Executive-Control and Working Memory Training in Older Adults. Psychol Sci. 2014;25(11):2027-37.

14. Soveri A, Antfolk J, Karlsson L, Salo B, Laine M. Working memory training revisited: A multi-level meta-analysis of n-back training studies. Psychon Bull Rev. 2017;24(4):1077-96.

15. Eschen A. The Contributions of Cognitive Trainings to the Stability of Cognitive, Everyday, and Brain Functioning across Adulthood. GeroPsych J Gerontopsychology Geriatr Psychiatry. 2012;25(4):22334.

16. Valenzuela M, Sachdev P. Can cognitive exercise prevent the onset of dementia? Systematic review of randomized clinical trials with longitudinal follow-up. Am J Geriatr Psychiatry. 2009;17(3):179-87.

17. Martin $M$, Clare L, Altgassen $A$, Cameron $M$, Zehnder F. Cognition-based interventions for healthy older people and people with mild cognitive impairment. Cochrane Database Syst Rev 2011. 2011; (1):1-48.

18. Gates N, Sachdev P, Singh MAF, Valenzuela M. Cognitive and memory training in adults at risk of dementia: A systematic review. BMC Geriatr. 2011;11(55):1-14.

19. Teixeira CVL, Gobbi LTB, Corazza DI, Stella F, Costa JLR, Gobbi S. Non-pharmacological interventions on cognitive functions in older people with mild cognitive impairment $(\mathrm{MCl})$. Arch Gerontol Geriatr. 2012;54(1):175-80.

20. Mewborn CM, Lindbergh CA, Stephen Miller L. Cognitive Interventions for Cognitively Healthy, Mildly Impaired, and Mixed Samples of Older Adults: A Systematic Review and Meta-Analysis of Randomized-Controlled Trials. Neuropsychology Review; 2017;27:403-439.

21. Zehnder F, Martin M, Altgassen M, Clare L. Memory training effects in old age as markers of plasticity: a meta-analysis. Restor Neurol Neurosci. 2009;27(5):507-20.

22. Olazarán J, Reisberg B, Clare L, Cruz I, Peña-Casanova J, Del Ser T, et al. Nonpharmacological therapies in alzheimer's disease: A systematic review of efficacy. Dement Geriatr Cogn Disord. 2010;30(2):161-78.

23. Hopper T, Bourgeois M, Pimentel J, Qualls CD, Hickey E, Frymark T, et al. An evidence-based systematic review on cognitive interventions for individuals with dementia. Am J Speech-Language Pathol. 2013;22(1):126-45.

24. Folkerts AK, Roheger M, Franklin J, Middelstädt J, Kalbe E. Cognitive interventions in patients with dementia living in long-term care facilities: Systematic review and meta-analysis. Arch Gerontol Geriatr. 2017;73:204-21. 
25. Ballard C, Khan Z, Clack H, Corbett A. Nonpharmacological treatment of Alzheimer disease. Can J Psychiatry. 2011;56(10):589-96.

26. Sitzer DI, Twamley EW, Jeste D V. Cognitive training in Alzheimer's disease: A meta-analysis of the literature. Acta Psychiatr Scand. 2006;114(2):75-90.

27. Rodakowski J, Saghafi E, Butters MA, Skidmore ER. Non-pharmacological Interventions for Adults with Mild Cognitive Impairment and Early Stage Dementia: An Updated Scoping Review. Mol Asp Med. 2015;43-44:38-53.

28. Kurz AF, Leucht S, Lautenschlager NT. The clinical significance of cognition-focused interventions for cognitively impaired older adults: A systematic review of randomized controlled trials. Int Psychogeriatrics. 2011;23(9):1364-75.

29. Huntley JD, Gould RL, Liu K, Smith M, Howard RJ. Do cognitive interventions improve general cognition in dementia? A meta-analysis and meta-regression. BMJ Open. 2015;5(4).

30. Bahar-Fuchs A, Clare L, Woods B. Cognitive training and cognitive rehabilitation for persons with mild to moderate dementia of the Alzheimer's or vascular type: a review. Alzheimers Res Ther. 2013;5(4):35.

31. Buschert V, Bokde ALW, Hampel H. Cognitive intervention in Alzheimer disease. Nat Rev Neurol. 2010;6(9):508-17.

32. Spector A, Orrell M, Hall L. Systematic review of neuropsychological outcomes in dementia from cognition-based psychological interventions. Dement Geriatr Cogn Disord. 2012;34(3-4):244-55.

33. Kueider AM, Parisi JM, Gross AL, Rebok GW. Computerized cognitive training with older adults: a systematic review. PLoS One. 2012;7(7):e40588.

34. Lampit A, Hallock H, Valenzuela M. Computerized Cognitive Training in Cognitively Healthy Older Adults: A Systematic Review and Meta-Analysis of Effect Modifiers. PLoS Med. 2014;11(11).

35. Tetlow AM, Edwards JD. Systematic Literature Review and Meta-Analysis of Commercially Available Computerized Cognitive Training Among Older Adults. J Cogn Enhanc. 2017;1(4):559-75.

36. Shah TM, Weinborn M, Verdile G, Sohrabi HR, Martins RN. Enhancing Cognitive Functioning in Healthly Older Adults: a Systematic Review of the Clinical Significance of Commercially Available Computerized Cognitive Training in Preventing Cognitive Decline. Neuropsychol Rev. 2017;27(1):6280.

37. Edwards JD, Fausto BA, Tetlow AM, Corona RT, Valdés EG. Systematic review and meta-analyses of useful field of view cognitive training. Neurosci Biobehav Rev. 2018;84(March 2017):72-91.

38. García-Casal JA, Loizeau A, Csipke E, Franco-Martín M, Perea-Bartolomé MV, Orrell M. Computerbased cognitive interventions for people living with dementia: a systematic literature review and meta-analysis. Aging Ment Health. 2016;21(5):454-67.

39. Liang J, Yong X, Lin L, Jia R, Zhang H, Hang L. Comparison of multiple interventions for older adults with Alzheimer disease or mild cognitive impairment A PRISMA-compliant network meta-analysis. Medicine (Baltimore). 2018;97:20(e107). 
40. Hill NTM, Mowszowski L, Naismith SL, Chadwick VL, Valenzuela M, Lampit A. Computerized cognitive training in older adults with mild cognitive impairment or dementia: A systematic review and meta-analysis. Am J Psychiatry. 2017;174(4):329-40.

41. Sood P, Kletzel SL, Krishnan S, Devos H, Negm A, Hoffecker L, et al. Nonimmersive Brain Gaming for Older Adults With Cognitive Impairment: A Scoping Review. Gerontologist. 2019; doi: 10.1093/geront/gny164.

42. Toril P, Reales JM, Ballesteros S. Video Game Training Enhances Cognition of Older Adults: A MetaAnalytic Study. Psychol Aging. 2014;29(3):706-16.

43. Wang P, Zhu X-T, Qi Z, Huang S, Li H-J. Neural Basis of Enhanced Executive Function in Older Video Game Players: An fMRI Study. Front Aging Neurosci. 2017;9(382):1-9.

44. Schultheis MT, Rizzo AA. The application of virtual reality technology in rehabilitation. Rehabil Psychol. 2001;46(3):296-311.

45. Jeral J. The VR Book: Human-Centred Design for Virtual Reality. The Association for Computing Machinery and Morgan \& Claypool Publishers; 2016.

46. Sutherland J, La Russa D. Virtual Reality. In: Rybicki FJ, Grant GT, editors. 3D Printing in Medicine. Springer International Publishing AG; 2017.

47. da Costa RQM, Pompeu JE, de Mello DD, Moretto E, Rodrigues FZ, dos Santos MD, et al. Two new virtual reality tasks for the assessment of spatial orientation. Dement Neuropsychol. 2018;12(2):196-204.

48. Harvey PD, Cosentino S, Curiel R, Goldberg TE, Kaye J, Loewenstein D, et al. Performance-based and observational assessments in clinical trials across the alzheimer's disease spectrum. Innov Clin Neurosci. 2017;14(1-2):30-9.

49. Negut A, Matu S-A, Sava FA, David D. Virtual reality measures in neuropsychological assessment: A meta-analytic review. Clin Neuropsychol. 2016;30(2):165-84.

50. Zygouris S, Ntovas K, Giakoumis D, Votis K, Doumpoulakis S, Segkouli S, et al. A Preliminary Study on the Feasibility of Using a Virtual Reality Cognitive Training Application for Remote Detection of Mild Cognitive Impairment. J Alzheimer's Dis. 2017;56(2):619-27.

51. Dascal J, Reid M, Ishak WW, Spiegel B, Recacho J, Rosen B, et al. Virtual Reality and Medical Inpatients: A Systematic Review of Randomized, Controlled Trials. Innov Clin Neurosci. 2017;14(12):14-21.

52. Dehn LB, Kater L, Piefke M, Botsch M, Driessen M, Beblo T. Training in a comprehensive everyday-like virtual reality environment compared to computerized cognitive training for patients with depression. Comput Human Behav. 2018;79:40-52.

53. Didehbani N, Allen T, Kandalaft M, Krawczyk D, Chapman S. Virtual Reality Social Cognition Training for children with high functioning autism. Comput Human Behav. 2016;62:703-11.

54. García-Betances RI, Cabrera-Umpiérrez MF, Arredondo MT. Computerized neurocognitive interventions in the context of the brain training controversy. Rev Neurosci. 2017; 
55. La Paglia F, La Cascia C, Rizzo R, Sanna M, Cangialosi F, Sideli L, et al. Virtual reality environments to rehabilitation attention deficits in schizophrenic patients. Annu Rev CyberTherapy Telemed. 2016;14:143-8.

56. Pourmand A, Davis S, Lee D, Barber S, Sikka N. Emerging Utility of Virtual Reality as a Multidisciplinary Tool in Clinical Medicine. Games Health J. 2017;6(5):263-70.

57. Riva G, Baños RM, Botella C, Mantovani F, Gaggioli A. Transforming experience: The potential of augmented reality and virtual reality for enhancing personal and clinical change. Front Psychiatry. 2016;7:1-14.

58. Garcia-Betances RI, Jimenez-Mixco V, Arredondo MT, Cabrera-Umpierrez MF. Using virtual reality for cognitive training of the elderly. Am J Alzheimers Dis Other Demen. 2014;30(1):49-54.

59. Rizzo AA, Buckwalter JG, McGee JS, Bowerly T, Zaag C van der, Neumann U, et al. Virtual Environments for Assessing and Rehabilitating Cognitive/Functional Performance A Review of Projects at the USC Integrated Media Systems Center. Presence Teleoperators Virtual Environ. 2001;10(4):359-74.

60. Schuchat J, Ouellet É, Moffat N, Belleville S. Opportunities for Virtual Reality in Cognitive Training with Persons with Mild Cognitive Impairment or Alzheimer's Disease. Non-Pharmalogical Ther Dement. 2012;3(1):35-54.

61. Arlati S, Greci L, Mondellini M, Zangiacomi A, Di Santo SG, Franchini F, et al. A Virtual Reality-Based Physical and Cognitive Training System Aimed at Preventing Symptoms of Dementia. In: Perego P, Rahmani AM, TeheriNejad N, editors. Wireless Mobile Communication and Healthcare. MobiHealth 2017. Springer, Cham; 2018. doi: 10.1007/978-3-319-98551-0_14

62. Parsons TD. Virtual Reality for Enhanced Ecological Validity and Experimental Control in the Clinical, Affective and Social Neurosciences. Front Hum Neurosci. 2015;9:1-19.

63. Repetto C, Serino S, Macedonia M, Riva G. Virtual reality as an embodied tool to enhance episodic memory in elderly. Front Psych. 2016. doi: 10.3389/fpsyg.2016.01839

64. Gamito P, Oliveira J, Coelho C, Morais D, Lopes P, Pacheco J, et al. Cognitive training on stroke patients via virtual reality-based serious games. Disabil Rehabil. 2017;39(4):385-8.

65. Zyda M. From visual simulation to virtual reality to games. Computer. 2005;38(9):25-32.

66. Manera V, Ben-Sadoun G, Aalbers T, Agopyan H, Askenazy F, Benoit M, et al. Recommendations for the use of serious games in neurodegenerative disorders: 2016 Delphi Panel. Front Physiol. 2017; doi: 10.3389/fpsyg.2017.01243.

67. Garcia L, Kartolo A, Methot-Curtis E. A Discussion of the Use of Virtual Reality in Dementia. In: Eichenberg Ch, editor. Virtual Reality in Psychological, Medical and Pedagogical Applications; 2012. doi: $10.5772 / 46412$

68. Coyle H, Traynor V, Solowij N. Computerized and Virtual Reality Cognitive Training for Individuals at High Risk of Cognitive Decline: Systematic Review of the Literature. Am J Geriatr Psychiatry. 2015;23(4):335-59. 
69. Eisapour M, Cao S, Domenicucci L, Boger J. Participatory Design of a Virtual Reality Exercise for People with Mild Cognitive Impairment. In: Extended Abstracts of the $2018 \mathrm{CHI}$ Conference on Human Factors in Computing Systems - CHI '18. 2018. doi:10.1145/3170427.3174362

70. Ali Mirza R, Yaqoob I. Effects Of Combined Aerobic And Virtual Reality-based Cognitive Training On 76 Years Old Diabetic Male With Mild Cognitive Impairment. J Coll Physicians Surg Pak. 2018; doi: 10.29271/jcpsp.2018.09.S210.

71. Mrakic-Sposta S, Di Santo SG, Franchini F, Arlati S, Zangiacomi A, Greci L, et al. Effects of combined physical and cognitive virtual reality-based training on cognitive impairment and oxidative stress in MCl patients: A pilot study. Front Aging Neurosci. 2018; doi: 10.3389/fnagi.2018.00282.

72. Zając-Lamparska L, Wiłkość-Dębczyńska M, Kędziora-Kornatowska K, Wojciechowski A, Warchoł $t$, Izdebski P. Virtual reality in cognitive interventions for older adults and its application in the GRADYS training software. Gerontol Pol. 2017;25:248-53.

73. Fritz CO, Morris PE, Richler JJ. Effect size estimates: Current use, calculations, and interpretation. J Exp Psychol Gen. 2012;141(1):2-18.

\section{Tables}

Table 1

\begin{tabular}{|c|c|c|c|c|}
\hline & \multicolumn{2}{|c|}{$\begin{array}{l}\text { Non-demented older adults } \\
\quad(\mathrm{n}=72,54 \text { women })\end{array}$} & \multirow{2}{*}{$\begin{array}{l}\text { Older adults with mild dementia } \\
\qquad M\end{array}$} & \multirow{2}{*}{$\begin{array}{c}(\mathrm{n}=27,22 \text { women }) \\
S D\end{array}$} \\
\hline & $M$ & $S D$ & & \\
\hline Age & 67.861 & 5.829 & 72.037 & 7.434 \\
\hline Yeas of education & 13.606 & 3.864 & 12.577 & 3.325 \\
\hline MMSE & 28.694 & 1.217 & 22.33 & 1.209 \\
\hline ACE - III & 91.139 & 6.374 & 75.667 & 14.959 \\
\hline
\end{tabular}

Table 2

GRADYS game development and evaluation process in the laboratory phase, based on the scheme proposed by Schulz et al. (2015) 


\section{Steps/Stages}

Activity/Work

Methods

(in Lab)

\begin{tabular}{|c|c|c|}
\hline $\begin{array}{l}\text { User-centred } \\
\text { design } \\
\text { prototype }\end{array}$ & $\begin{array}{l}\text { Designing gameplay scenarios and cognitive tasks involved therein. } \\
\text { Designing the game interface and solutions for the mechanism } \\
\text { underlying interaction with the game, the navigation mechanisms, the } \\
\text { rules of promotion to the next level in the game and how to } \\
\text { communicate with a player and inform them about their results. } \\
\text { Planning on a set of technical solutions necessary to navigate the } \\
\text { game. }\end{array}$ & $\begin{array}{l}\text { Storyboarding; } \\
\text { Individual in-depth } \\
\text { interviews; } \\
\text { Focus group. }\end{array}$ \\
\hline $\begin{array}{l}\text { Robust } \\
\text { prototype }\end{array}$ & $\begin{array}{l}\text { Programming the game while taking into account all the aspects } \\
\text { mentioned above, selecting graphic environment and the assets. } \\
\text { Testing the game software and solutions applied therein as well as } \\
\text { technical solutions and devices used. }\end{array}$ & $\begin{array}{l}\text { Laboratory testing } \\
\text { Scenario testing; } \\
\text { Observation of task } \\
\text { performing (by the } \\
\text { team members). }\end{array}$ \\
\hline $\begin{array}{l}\text { Laboratory } \\
\text { prototype }\end{array}$ & $\begin{array}{l}\text { Testing the target set of software and hardware, including final game } \\
\text { scenario as well as the mechanisms for interaction between player and } \\
\text { game and navigation mechanisms with regard to their user- } \\
\text { friendliness, intuitive simplicity, and learnability. }\end{array}$ & $\begin{array}{l}\text { Observation of task } \\
\text { performing (by the } \\
\text { targeted end users } \\
\text { and the team } \\
\text { members); "Think } \\
\text { aloud" (by the } \\
\text { targeted end users); } \\
\text { Focus group. }\end{array}$ \\
\hline
\end{tabular}

Table 3

A comparison of baseline cognitive performance in groups of non-demented older adults and older adults with mild dementia: the Student's $t$ test and the Mann-Whitney $U$ test ${ }^{a}$ 


\begin{tabular}{|c|c|c|c|c|c|}
\hline \multirow[t]{2}{*}{ Cognitive measures } & \multicolumn{3}{|c|}{$\begin{array}{l}\text { The Student's } t \text { test/ } \\
\text { the Welch's } t \text { test }^{\mathrm{b}}\end{array}$} & \multicolumn{2}{|c|}{ The Mann-Whitney $U$ test } \\
\hline & $t^{\mathrm{b}}$ & $p \quad \mathrm{He}$ & es's $g$ & $Z$ corr. $^{\mathrm{C}}$ & $p$ \\
\hline Digit Symbol WAIS - R (PL) & 2.899 & .005 & 0.65 & 2.748 & .006 \\
\hline CTT-1 time & $-2.301^{\mathrm{d}}$ & .029 & 0.76 & -2.986 & .003 \\
\hline CTT-1 errors & $-1.185^{\mathrm{d}}$ & .244 & 0.32 & -1.427 & .153 \\
\hline CTT-2 time & $-2.361^{\mathrm{d}}$ & .025 & 0.71 & -3.041 & .002 \\
\hline CTT-2 errors & $-1.457^{d}$ & .156 & 0.45 & -2.178 & .029 \\
\hline $\mathrm{d} 2 \mathrm{WZ}$ & -2.848 & .005 & 0.68 & -2.829 & .005 \\
\hline d2 \%B & $1.021^{\mathrm{d}}$ & .474 & 0.16 & -0.519 & .604 \\
\hline d2 WZ-B & -2.396 & .019 & 0.54 & -2.675 & .007 \\
\hline d2 ZK & 1.014 & .310 & 0.23 & 1.226 & .220 \\
\hline Block Design WAIS - R (PL) & 3.018 & .003 & 0.68 & 2.426 & .015 \\
\hline ROCF copy & $2.332^{\mathrm{d}}$ & .026 & 0.63 & 2.759 & .006 \\
\hline ROCF delayed recall & 3.727 & $<.001$ & 0.83 & 3.502 & $<.001$ \\
\hline Digit span - forward WAIS - R (PL) & 0.255 & .799 & 0.06 & 0.619 & .536 \\
\hline Digit span - backward WAIS - R (PL) & 2.683 & .009 & 0.60 & 2.426 & .015 \\
\hline AVLT list $\mathrm{A}$, trial 1 & 2.579 & .011 & 0.58 & 2.319 & .020 \\
\hline AVLT list $\mathrm{A}$, trial 5 & 5.528 & $<.001$ & 1.24 & 4.558 & $<.001$ \\
\hline AVLT list B & $3.324^{\mathrm{d}}$ & .001 & 0.57 & 3.042 & .002 \\
\hline AVLT list A, trial 6 & 4.414 & $<.001$ & 0.99 & 3.949 & $<.001$ \\
\hline AVLT list A, trial 7 & 4.961 & $<.001$ & 1.11 & 4.206 & $<.001$ \\
\hline AVLT list A, recognition & $0.221^{\mathrm{d}}$ & .827 & 0.07 & 1.729 & .084 \\
\hline BVRT correct reproductions indicator & 3.333 & .001 & 0.75 & 2.873 & .004 \\
\hline BVRT errors indicator & $-3.642^{d}$ & $<.001$ & 0.95 & -3.398 & $<.001$ \\
\hline Famous Faces Test & $4.778^{\mathrm{d}}$ & $<.001$ & 1.28 & 4.713 & $<.001$ \\
\hline Verbal Fluency (ACE-III) & 3.967 & $<.001$ & 0.89 & 3.192 & .001 \\
\hline Boston Naming Test & $2.163^{d}$ & .038 & 0.63 & 1.958 & .050 \\
\hline
\end{tabular}

Note:

a The means and standard deviations for all above mentioned cognitive measures in both research groups are presented in Table 7 which contains the means and standard deviations for both groups in pretest and posttest ${ }^{\mathrm{b}}$ If the Levene's test indicated the unequality of variances, the Welch's $t$ test was calculated.

${ }^{\mathrm{c}}$ Correction for ties in the ranking.

d The Welch's $t$ test.

Table 4

A comparison of difficulty levels achieved in subsequent training sessions for each cognitive module in the groups of non-demented older adults and older adults with mild dementia (the Friedman's test) and a comparison of the groups as regards their ultimate difficulty level (Session 4) achieved in individual cognitive modules (the Mann-Whitney $U$ test) 


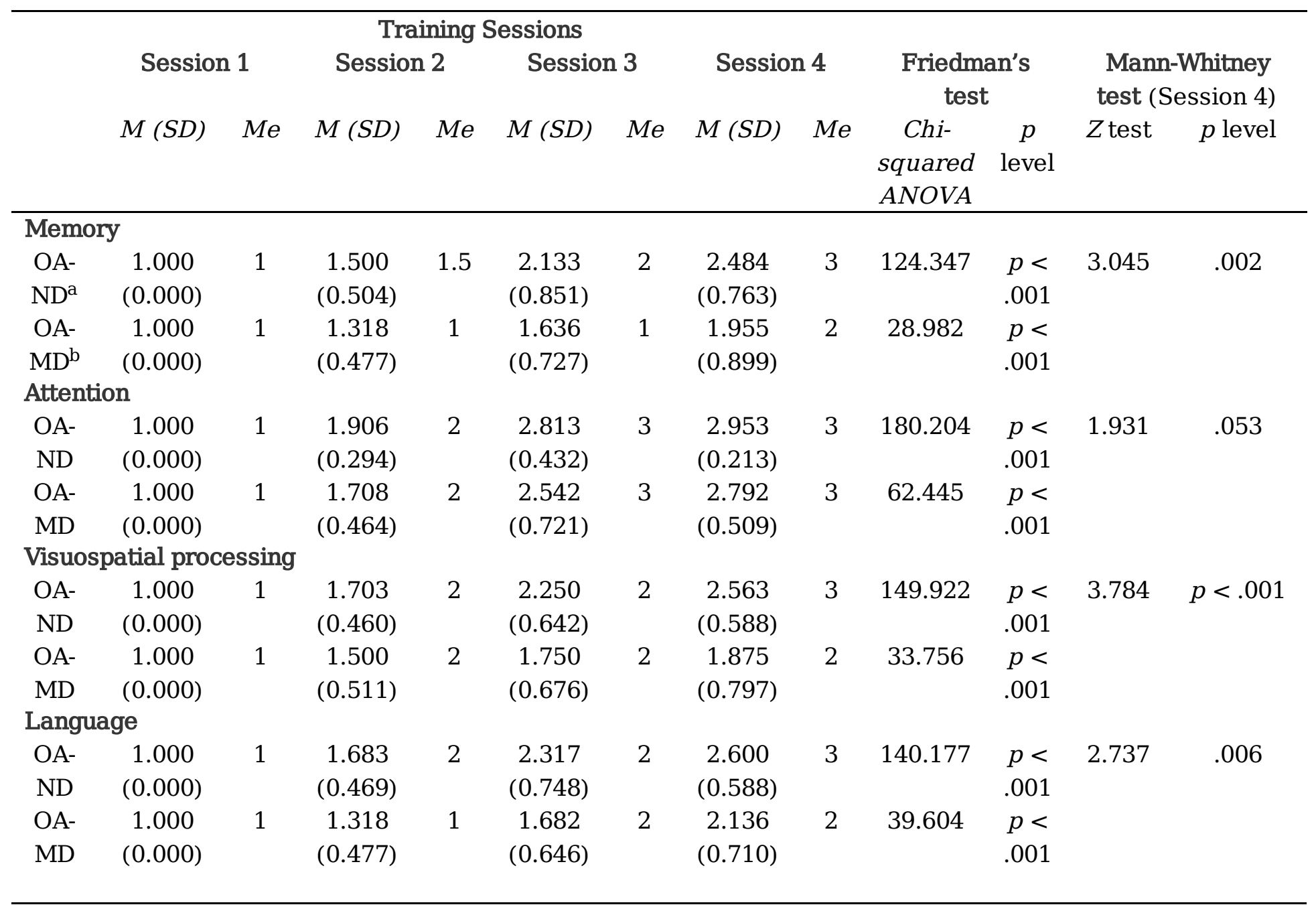

Note: $:$ OA-ND - Non-demented older adults; ${ }^{\mathrm{b}} \mathrm{OA}-\mathrm{MD}$ - Older adults with mild dementia

Table 5

Changes in cognitive functioning under the influence of training with the GRADYS game in the groups of non-demented older adults and older adults with mild dementia: RM MANOVA with a qualitative predictor ${ }^{\mathrm{a}}$ 


\begin{tabular}{|c|c|c|c|c|c|c|}
\hline Effect & & Value & $F$ & $p$ level & Partial Eta Squared & Observed power \\
\hline \multirow[t]{4}{*}{ Intercept } & Wilks' Lambda & 0.001 & 2307.172 & $p<.001$ & 0.999 & 1.000 \\
\hline & Pillai's Trace & 0.999 & 2307.172 & $p<.001$ & 0.999 & 1.000 \\
\hline & Hotelling's Trace & 790.127 & 2307.172 & $p<.001$ & 0.999 & 1.000 \\
\hline & Roy Largest Root & 790.127 & 2307.172 & $p<.001$ & 0.999 & 1.000 \\
\hline \multirow[t]{4}{*}{ Group } & Wilks' Lambda & 0.471 & 3.285 & $p<.001$ & 0.529 & 1.000 \\
\hline & Pillai's Trace & 0.529 & 3.285 & $p<.001$ & 0.529 & 1.000 \\
\hline & Hotelling's Trace & 1.125 & 3.285 & $p<.001$ & 0.529 & 1.000 \\
\hline & Roy Largest Root & 1.125 & 3.285 & $p<.001$ & 0.529 & 1.000 \\
\hline \multirow[t]{4}{*}{ Training } & Wilks' Lambda & 0.613 & 1.840 & .023 & 0.387 & 0.969 \\
\hline & Pillai's Trace & 0.387 & 1.840 & .023 & 0.387 & 0.969 \\
\hline & Hotelling's Trace & 0.630 & 1.840 & .023 & 0.387 & 0.969 \\
\hline & Roy Largest Root & 0.630 & 1.840 & .023 & 0.387 & 0.969 \\
\hline \multirow[t]{4}{*}{ Training*Group } & Wilks' Lambda & 0.652 & 1.562 & .073 & 0.349 & 0.930 \\
\hline & Pillai's Trace & 0.349 & 1.562 & .073 & 0.349 & 0.930 \\
\hline & Hotelling's Trace & 0.535 & 1.562 & .073 & 0.349 & 0.930 \\
\hline & Roy Largest Root & 0.535 & 1.562 & .073 & 0.348 & 0.930 \\
\hline
\end{tabular}

Note:

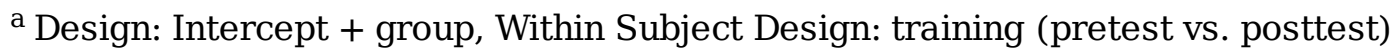

Table 6

Changes in cognitive functioning under the influence of training with the GRADYS game: RM MANOVA computed separately in two research groups: non-demented older adults and older adults with mild dementia 


\begin{tabular}{|c|c|c|c|c|c|c|c|}
\hline Group & Effect & & Value & $F$ & $p$ level & $\begin{array}{c}\text { Partial Eta } \\
\text { Squared }\end{array}$ & $\begin{array}{c}\text { Observed } \\
\text { power }\end{array}$ \\
\hline \multirow[t]{8}{*}{$\begin{array}{l}\mathrm{OA}^{-} \\
\mathrm{ND}^{\mathrm{a}}\end{array}$} & \multirow[t]{4}{*}{ Intercept } & Wilks' Lambda & 0.001 & 3078.744 & $\begin{array}{l}p< \\
.001\end{array}$ & 0.999 & 1.000 \\
\hline & & Pillai's Trace & 0.999 & 3078.744 & $\begin{array}{l}p< \\
.001\end{array}$ & 0.999 & 1.000 \\
\hline & & $\begin{array}{l}\text { Hotelling's } \\
\text { Trace }\end{array}$ & 1637.630 & 3078.744 & $\begin{array}{l}p< \\
.001\end{array}$ & 0.999 & 1.000 \\
\hline & & $\begin{array}{l}\text { Roy Largest } \\
\text { Root }\end{array}$ & 1637.630 & 3078.744 & $\begin{array}{l}p< \\
.001\end{array}$ & 0.999 & 1.000 \\
\hline & \multirow[t]{4}{*}{ Training } & Wilks' Lambda & 0.326 & 3.879 & $\begin{array}{l}p< \\
.001\end{array}$ & 0.674 & 1.000 \\
\hline & & Pillai's Trace & 0.674 & 3.879 & $\begin{array}{l}p< \\
.001\end{array}$ & 0.674 & 1.000 \\
\hline & & $\begin{array}{l}\text { Hotelling's } \\
\text { Trace }\end{array}$ & 2.063 & 3.879 & $\begin{array}{l}p< \\
.001\end{array}$ & 0.674 & 1.000 \\
\hline & & $\begin{array}{l}\text { Roy Largest } \\
\text { Root }\end{array}$ & 2.063 & 3.879 & $\begin{array}{l}p< \\
.001\end{array}$ & 0.674 & 1.000 \\
\hline \multirow{8}{*}{$\begin{array}{l}\text { OA- } \\
\mathrm{MD}^{\mathrm{a}}\end{array}$} & \multirow[t]{4}{*}{ Intercept } & Wilks' Lambda & 0.000 & 336.666 & .003 & 1.000 & 0.969 \\
\hline & & Pillai's Trace & 1.000 & 336.666 & .003 & 1.000 & 0.969 \\
\hline & & $\begin{array}{l}\text { Hotelling's } \\
\text { Trace }\end{array}$ & 4208.325 & 336.666 & .003 & 1.000 & 0.969 \\
\hline & & $\begin{array}{l}\text { Roy Largest } \\
\text { Root }\end{array}$ & 4208.325 & 336.666 & .003 & 1.000 & 0.969 \\
\hline & \multirow[t]{4}{*}{ Training } & Wilks' Lambda & 0.652 & 1.562 & .242 & 0.978 & 0.208 \\
\hline & & Pillai's Trace & 0.349 & 1.562 & .242 & 0.978 & 0.208 \\
\hline & & $\begin{array}{l}\text { Hotelling's } \\
\text { Trace }\end{array}$ & 0.535 & 1.562 & .242 & 0.978 & 0.208 \\
\hline & & $\begin{array}{l}\text { Roy Largest } \\
\text { Root }\end{array}$ & 0.535 & 1.562 & .242 & 0.978 & 0.208 \\
\hline
\end{tabular}

Note:

${ }^{\text {a }}$ OA-ND - non-demented older adults; OA-MD - older adults with mild dementia

Table 7

The differences between pretest and posttest for particular cognitive measures in the groups of nondemented older adults and older adults with mild dementia. One-way tests computed separately in both groups 


\begin{tabular}{|c|c|c|c|c|c|c|}
\hline Cognitive measures & Groups & $\begin{array}{c}\text { Pretest } M \\
(S D)\end{array}$ & $\begin{array}{c}\text { Posttest } M \\
\text { (SD) }\end{array}$ & $\begin{array}{c}\text { Fisher's } \\
F\end{array}$ & $\begin{array}{c}p \\
\text { value }\end{array}$ & $\begin{array}{c}\text { Partial eta } \\
\text { squared }\end{array}$ \\
\hline \multirow[t]{4}{*}{ Digit Symbol WAIS - R (PL) } & OA- & 39.917 & 41.859 & 3.450 & .067 & 0.046 \\
\hline & $\mathrm{ND}^{\mathrm{a}}$ & (13.883) & (10.801) & 1.183 & .286 & 0.044 \\
\hline & OA- & 30.962 & 32.067 & & & \\
\hline & $\mathrm{MD}^{\mathrm{b}}$ & (13.347) & (13.904) & & & \\
\hline \multirow{4}{*}{ CTT-1 time } & OA-ND & 67.389 & 61.930 & 2.952 & .090 & 0.040 \\
\hline & OA-MD & (27.690) & (22.843) & 1.318 & .261 & 0.048 \\
\hline & & 105.667 & 88.080 & & & \\
\hline & & (84.748) & $(40.528)$ & & & \\
\hline \multirow[t]{2}{*}{ CTT-1 errors } & OA-ND & $0.097(0.342)$ & $0.028(0.166)$ & 2.816 & .098 & 0.038 \\
\hline & OA-MD & $0.222(0.506)$ & $0.040(0.192)$ & 2.933 & .099 & 0.101 \\
\hline \multirow[t]{4}{*}{ CTT-2 time } & OA-ND & 130.014 & 120.761 & 5.167 & .026 & 0.068 \\
\hline & OA-MD & (51.600) & (45.302) & 1.670 & 208 & 0.060 \\
\hline & & 180.815 & 193.960 & & & \\
\hline & & (107.236) & (122.325) & & & \\
\hline \multirow[t]{2}{*}{ CTT-2 errors } & OA-ND & $0.222(0.717)$ & $0.211(0.579)$ & 0.017 & .898 & 0.0002 \\
\hline & OA-MD & $0.704(1.660)$ & $0.520(1.244)$ & 0.896 & 352 & 0.033 \\
\hline \multirow[t]{4}{*}{ d2 WZ } & OA-ND & 316.493 & 350.901 & 18.287 & $p<$ & 0.205 \\
\hline & OA-MD & (125.297) & (143.112) & 0.162 & .001 & 0.006 \\
\hline & & 392.958 & 387.318 & & 691 & \\
\hline & & (99.711) & (118.466) & & & \\
\hline \multirow[t]{4}{*}{ d2 \%B } & OA-ND & 23.870 & 15.273 & 5.838 & .018 & 0.076 \\
\hline & OA-MD & (34.578) & (14.907) & 4.364 & .047 & 0.144 \\
\hline & & 18.945 & 16.299 & & & \\
\hline & & (13.410) & (11.794) & & & \\
\hline \multirow[t]{4}{*}{ d2 WZ-B } & OA-ND & 256.155 & 300.167 & 42.946 & $p<$ & 0.377 \\
\hline & OA-MD & (126.183) & (134.440) & 0.382 & .001 & 0.014 \\
\hline & & 320.708 & 328.00 & & .542 & \\
\hline & & (98.540) & (116.011) & & & \\
\hline \multirow[t]{4}{*}{ d2 ZK } & OA-ND & 111.329 & 129.690 & 14.674 & $p<$ & 0.171 \\
\hline & OA-MD & $(47.701)$ & (50.946) & 1.005 & .001 & 0.047 \\
\hline & & 100.375 & 105.903 & & .325 & \\
\hline & & $(48.374)$ & $(48.714)$ & & & \\
\hline \multirow[t]{4}{*}{ Block Design WAIS - R (PL) } & OA-ND & 21.833 & $24.183(8.118)$ & 12.509 & $p<$ & 0.150 \\
\hline & OA-MD & (8.454) & $17.017(9.433)$ & 2.433 & .001 & 0.086 \\
\hline & & 15.852 & & & 131 & \\
\hline & & (9.623) & & & & \\
\hline \multirow[t]{4}{*}{ ROCF copy } & OA-ND & 33.028 & 33.809 (2.893) & 1.804 & 184 & 0.025 \\
\hline & OA-MD & (4.663) & $32.562(4.878)$ & 8.867 & .006 & 0.254 \\
\hline & & 29.596 & & & & \\
\hline & & (7.094) & & & & \\
\hline \multirow[t]{3}{*}{ ROCF delayed recall } & OA-ND & 19.146 & 21.735 (7.233) & 9.795 & .003 & 0.121 \\
\hline & OA-MD & (8.329) & $12.945(6.811)$ & 0.216 & .646 & 0.008 \\
\hline & & $\begin{array}{l}12.481 \\
(6.693)\end{array}$ & & & & \\
\hline Digit span - forward & OA-ND & $5.693(1.931)$ & $5.704(1.731)$ & 0.210 & .648 & 0.003 \\
\hline
\end{tabular}




\begin{tabular}{|c|c|c|c|c|c|c|}
\hline WAIS - R (PL) & OA-MD & $5.519(2.471)$ & $5.269(2.176)$ & 0.651 & .427 & 0.024 \\
\hline Digit span - backward & OA-ND & $5.042(1.699)$ & $5.479(1.635)$ & 6.619 & .012 & 0.085 \\
\hline WAIS - R (PL) & OA-MD & $3.963(1.190)$ & 3.769 (1.219) & 0.435 & .515 & 0.016 \\
\hline \multirow[t]{2}{*}{ AVLT list A, trial 1} & OA-ND & $5.268(1.784)$ & $5.409(1.553)$ & 0.353 & .555 & 0.005 \\
\hline & OA-MD & $4.259(1.583)$ & $4.346(1.413)$ & 0.089 & .767 & 0.003 \\
\hline \multirow[t]{3}{*}{ AVLT list A, trial 5} & OA-ND & 11.437 & $11.310(2.481)$ & 0.268 & .606 & 0.004 \\
\hline & OA-MD & $(2.354)$ & $8.692(2.126)$ & 0.694 & .412 & 0.026 \\
\hline & & $8.407(2.620)$ & & & & \\
\hline \multirow[t]{2}{*}{ AVLT list B } & OA-ND & $5.113(2.140)$ & $4.634(2.050)$ & 2.848 & .096 & 0.039 \\
\hline & OA-MD & $4.000(1.144)$ & $3.962(1.285)$ & 0.027 & .871 & 0.001 \\
\hline \multirow[t]{2}{*}{ AVLT list A, trial 6} & OA-ND & $9.070(3.069)$ & $9.366(3.181)$ & 0.894 & .348 & 0.012 \\
\hline & OA-MD & $6.037(2.981)$ & $6.500(3.153)$ & 0.623 & .437 & 0.023 \\
\hline \multirow[t]{2}{*}{ AVLT list A, trial 7} & OA-ND & $9.254(3.066)$ & $8.873(3.801)$ & 1.036 & .312 & 0.014 \\
\hline & OA-MD & $5.704(3.440)$ & $6.154(3.371)$ & 1.013 & .323 & 0.038 \\
\hline \multirow[t]{4}{*}{ AVLT list A, recognition } & OA-ND & 14.056 & $14.056(1.694)$ & 0.000 & 1.000 & 0.000 \\
\hline & OA-MD & $(1.727)$ & $13.360(4.419)$ & 0.272 & .607 & 0.010 \\
\hline & & 13.852 & & & & \\
\hline & & $(4.688)$ & & & & \\
\hline \multirow{2}{*}{$\begin{array}{l}\text { BVRT correct reproductions } \\
\text { indicator }\end{array}$} & OA-ND & $5.889(1.781)$ & $6.189(1.962)$ & 2.457 & .121 & 0.033 \\
\hline & OA-MD & $4.444(2.259)$ & $3.692(1.957)$ & 5.170 & .031 & 0.166 \\
\hline \multirow[t]{2}{*}{ BVRT errors indicator } & OA-ND & $6.292(3.009)$ & $5.455(3.125)$ & 7.234 & .009 & 0.092 \\
\hline & OA-MD & $9.519(4.219)$ & $9.885(4.585)$ & 0.221 & .643 & 0.008 \\
\hline \multirow[t]{2}{*}{ Famous Faces Test } & OA-ND & $9.583(1.432)$ & $9.471(1.774)$ & 0.544 & .463 & 0.008 \\
\hline & OA-MD & $7.444(2.154)$ & $7.600(2.465)$ & 0.154 & .698 & 0.006 \\
\hline \multirow[t]{3}{*}{ Verbal Fluency (ACE-III) } & OA-ND & 10.958 & $11.343(2.426)$ & 2.576 & .113 & 0.035 \\
\hline & OA-MD & $(2.236)$ & $8.630(3.628)$ & 0.070 & .794 & 0.003 \\
\hline & & $8.778(2.913)$ & & & & \\
\hline \multirow[t]{3}{*}{ Boston Naming Test } & OA-ND & 57.722 & $58.000(2.974)$ & 1.710 & .195 & 0.024 \\
\hline & OA-MD & (3.027) & $55.577(5.500)$ & 0.513 & .480 & 0.019 \\
\hline & & $\begin{array}{l}55.259 \\
(5.620)\end{array}$ & & & & \\
\hline
\end{tabular}

Note:

a OA-ND - non-demented older adults; ${ }^{\mathrm{b}} \mathrm{OA}-\mathrm{MD}$ - older adults with mild dementia

Table 8

A comparison of the cognitive measures changes (the posttest minus the pretest scores) in participants achieving different difficulty levels at the end of the training sessions in corresponding module, separate 
analysis in the groups of non-demented older adults and older adults with mild dementia (the Kruskal-Wallis test) 
Groups which achieved different final levels of difficulty in the training

\begin{tabular}{|c|c|c|c|c|c|c|c|c|c|c|}
\hline \multicolumn{3}{|c|}{ Level $3^{a}$} & \multicolumn{3}{|c|}{ Level $2^{\mathrm{a}}$} & \multicolumn{3}{|c|}{ Level $1^{\mathrm{a}}$} & \multicolumn{2}{|c|}{$\begin{array}{c}\text { Kruskal- } \\
\text { Wallis test }\end{array}$} \\
\hline$N$ & $M$ & $S D$ & $N$ & $M$ & $S D$ & $N$ & $M$ & $S D$ & $H$ & $\begin{array}{c}p \\
\text { level }\end{array}$ \\
\hline
\end{tabular}

\section{Memory}

OA-ND ${ }^{b}$

Digit span - forward WAIS - R (PL)

Digit span - backward WAIS R (PL)

AVLT list A, trial 1

AVLT list A, trial 5

AVLT list B

AVLT list A, trial 6

AVLT list A, trial 7

AVLT list A, recognition

BVRT correct reproductions

indicator

BVRT errors indicator ${ }^{d}$

Famous Faces Test

ROCF deleyed recall ${ }^{\mathrm{d}}$

OA-MD

Digit span - forward WAIS - R

(PL)

Digit span - backward WAIS -

R (PL)

AVLT list A, trial 1

AVLT list A, trial 5

AVLT list B

AVLT list A, trial 6

AVLT list A, trial 7

AVLT list A, recognition

BVRT correct reproductions
48

\section{$0.121 \quad 1.340$}

$0.585 \quad 1.440$

- $\quad 2.216$

0.013

- 2.009

0.376

- 2.095

0.306

$0.093 \quad 2.785$

- 2.928

0.194

- 2.020

0.297

$0.260 \quad 1.503$

$-1.026 \quad 2.474$

$0.041 \quad 1.069$

$3.047 \quad 7.813$

9$$
\text { (2.66 }
$$

$\begin{array}{cc}- & 1.581 \\ 0.667 & \end{array}$

0.225
$-\quad 1.667$

0.667

0.222

0.222

1.202

1.986

$0.000 \quad 1.095$

11

0.667

- 2.028

0.111

0.111

2.147

- 2.167

0.111

14

$\begin{array}{cc}- & 0.967 \\ 0.538 & \\ 0.000 & 1.291\end{array}$

$0.538 \quad 1.506$

$0.538 \quad 2.222$

- 2.213

0.692

$1.231 \quad 2.833$

$0.769 \quad 1.691$

$0.385 \quad 2.256$

$0.154 \quad 2.154$

3.282

0.462

$0.077 \quad 1.038$

$2.423 \quad 6.931$

$0.333 \quad 1.366$

$0.333 \quad 0.816$

$1.000 \quad 1.414$

$0.333 \quad 1.033$

$2.500 \quad 4.087$

$\begin{array}{ll}0.333 & 1.033\end{array}$

$0.833 \quad 1.722$

- 1.269
10

$\begin{array}{llll}0.500 & 0.527 & 5.854 & .054\end{array}$

$\begin{array}{llll}0.300 & 1.636 & 2.056 & .358\end{array}$

$\begin{array}{llll}0.773 & 1.337 & 0.716 & .699\end{array}$

$\begin{array}{llll}- & 2.171 & 1.951 & .377\end{array}$

0.044

$\begin{array}{llll}- & 2.321 & 1.203 & .548\end{array}$

0.911

$\begin{array}{llll}0.393 & 1.724 & 1.608 & .448\end{array}$

$\begin{array}{llll}- & 4.839 & 3.980 & .137\end{array}$

2.725

0.394

$\begin{array}{lll}1.724 & 1.946 \quad .378\end{array}$

$\begin{array}{llll}0.900 & 1.792 & 2.816 & .245\end{array}$

$\begin{array}{llll}- & 2.625 & 1.666 & .435\end{array}$

1.000

$\begin{array}{llll}- & 2.011 & 0.268 & .875\end{array}$

0.600

$\begin{array}{llll}0.600 & 2.654 & 1.081 & .582\end{array}$

11

$\begin{array}{llll}- & 1.973 & 0.814 & .666\end{array}$

0.091

$\begin{array}{llll}0.091 & 1.758 & 2.313 & .315\end{array}$

$\begin{array}{llll}0.000 & 1.949 & 0.911 & .634\end{array}$

$\begin{array}{llll}0.091 & 1.700 & 1.573 & .455\end{array}$

$\begin{array}{llll}0.091 & 1.300 & 3.976 & .137\end{array}$

$\begin{array}{llll}- & 2.806 \quad 2.893 \quad .235\end{array}$

0.455

$\begin{array}{llll}0.273 & 2.533 & 0.343 & .842\end{array}$

$\begin{array}{llll}- & 7.815 & 0.812 & .667\end{array}$

1.455

$\begin{array}{llll}0.000 & 1.844 & 3.723 & .156\end{array}$ 


\begin{tabular}{|c|c|c|c|c|c|c|c|c|c|c|c|}
\hline indicator $^{\mathrm{d}}$ & & 1.256 & & & 1.000 & & & & & & \\
\hline BVRT errors indicator & & 1.098 & 1.850 & & 1.167 & 4.167 & & 0.545 & 3.532 & 0.289 & .865 \\
\hline Famous Faces Test & & 0.778 & 1.787 & & 0.000 & 0.632 & & $\begin{array}{c}- \\
0.400\end{array}$ & 2.713 & 2.212 & .331 \\
\hline ROCF deleyed recall & & 2.667 & 3.824 & & $\begin{array}{c}- \\
0.083\end{array}$ & 2.498 & & $\begin{array}{c}- \\
0.412\end{array}$ & 6.729 & 1.852 & .396 \\
\hline $\begin{array}{l}\text { Visuospatial processing } \\
\text { OA-MD }\end{array}$ & 8 & & & 10 & & & 9 & & & & \\
\hline Block Design WAIS - R (PL) & & 0.750 & 3.918 & & 2.000 & 4.243 & & $\begin{array}{c}- \\
0.333\end{array}$ & 1.803 & 2.317 & .314 \\
\hline ROCF copyd & & 0.563 & 4.118 & & 4.222 & 4.251 & & 4.552 & 6.223 & 4.020 & .134 \\
\hline Language & & & & & & & & & & & \\
\hline OA-MD & 10 & & & 12 & & & 5 & & & & \\
\hline Verbal fluency (ACE III) & & 0.667 & 2.693 & & $\begin{array}{c}- \\
0.417\end{array}$ & 3.343 & & 0.250 & 1.708 & 0.340 & .844 \\
\hline Boston Naming Test & & $\begin{array}{c}- \\
0.222\end{array}$ & 1.563 & & 0.333 & 2.498 & & 1.250 & 2.217 & 1.243 & .537 \\
\hline
\end{tabular}

Note:

aThe difficulty increases from level 1 (the easiest one) to level 3 (the most difficult one)

bOA-ND - Non-demented older adults

${ }^{\mathrm{c} O A-M D}$ - Older adults with mild dementia

${ }^{\mathrm{d} O u t c o m e}$ measures for which significant differences between pretest and posttest were noted

Table 9

A comparison of the cognitive measures changes (the posttest minus the pretest scores) in non-demented older adults ending training at the maximum difficulty level in corresponding module or below (the MannWhitney U test)

\begin{tabular}{|c|c|c|c|c|c|c|c|c|}
\hline & \multicolumn{6}{|c|}{$\begin{array}{c}\text { Groups which achieved different final levels of difficulty in the } \\
\text { training }\end{array}$} & \multirow{2}{*}{\multicolumn{2}{|c|}{$\begin{array}{l}\text { Mann-Whitney } \\
\text { test }\end{array}$}} \\
\hline & \multicolumn{3}{|c|}{ Level $3^{a}$} & \multicolumn{3}{|c|}{ Level 2 and $1^{\mathrm{a}}$} & & \\
\hline & $N$ & $M$ & $S D$ & $N$ & $M$ & $S D$ & $Z$ & $p$ level \\
\hline Visuospatial processing & & & & & & & & \\
\hline OA-ND ${ }^{b}$ & 44 & & & 28 & & & & \\
\hline $\begin{array}{l}\text { Block Design WAIS - R } \\
\text { (PL) }\end{array}$ & & 1.423 & 6.243 & & 3.731 & 4.396 & -1.303 & .193 \\
\hline ROCF copy ${ }^{\mathrm{C}}$ & & 0.975 & 5.707 & & 0.327 & 3.616 & 0.3147 & .754 \\
\hline Language & & & & & & & & \\
\hline OA-ND & 45 & & & 27 & & & & \\
\hline Verbal fluency (ACE III) & & 0.365 & 2.311 & & 0.280 & 1.458 & 0.620 & .535 \\
\hline Boston Naming Test & & 0.279 & 1.804 & & 0.000 & 1.803 & 0.418 & .676 \\
\hline
\end{tabular}


Note:

aThe difficulty increases from level 1 (the easiest) to level 3 (the most difficult one)

bOA-ND - Non-demented older adults

${ }^{\mathrm{C}}$ Outcome measures for which significant differences between pretest and posttest were noted

\section{Figures}

Figure 1

Sample screens from the GRADYS game: (a) location "at home"; (b) location "out of home".

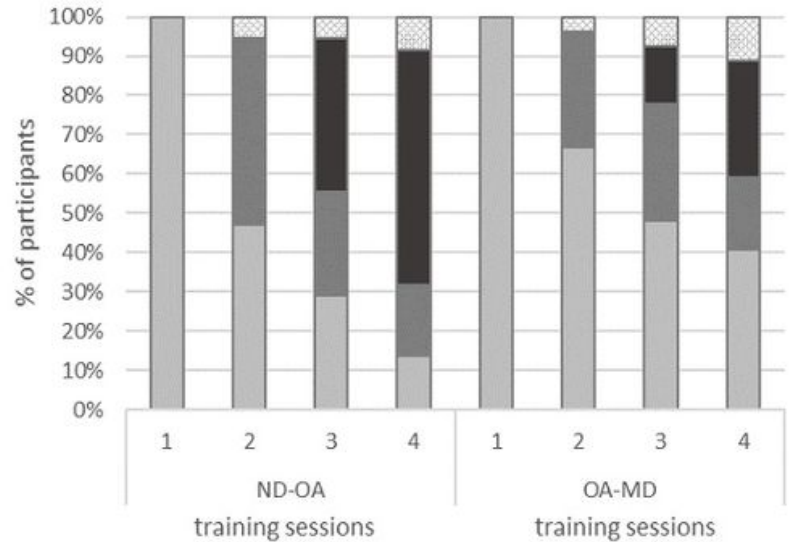

(a)

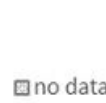

mlevel 3

घlevel 2

口level 1

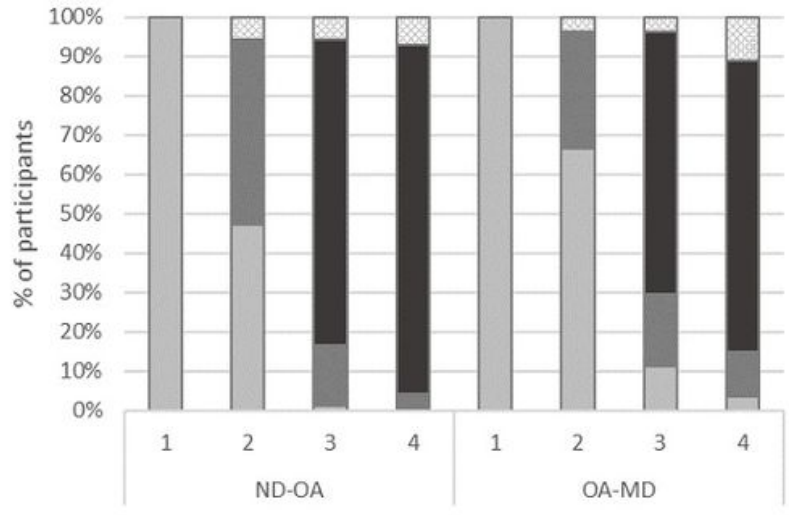

(b)

no data

= level 3

alevel 2

ㅁevel 1

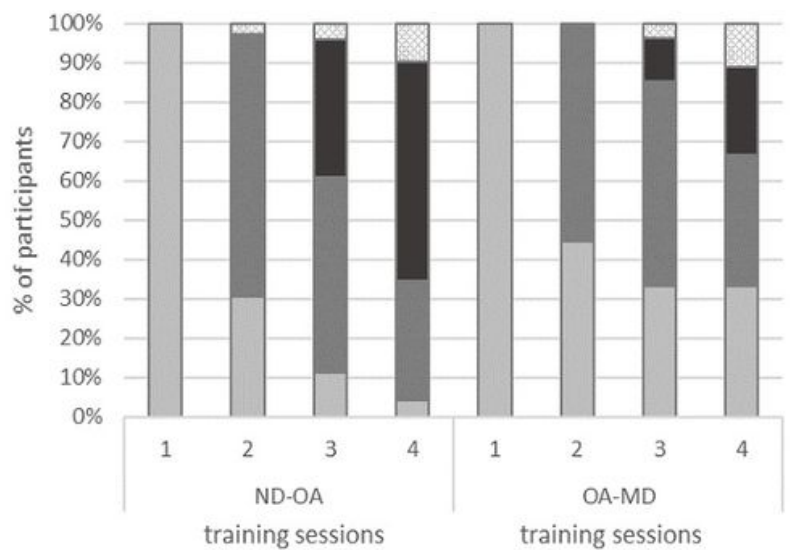

(c)
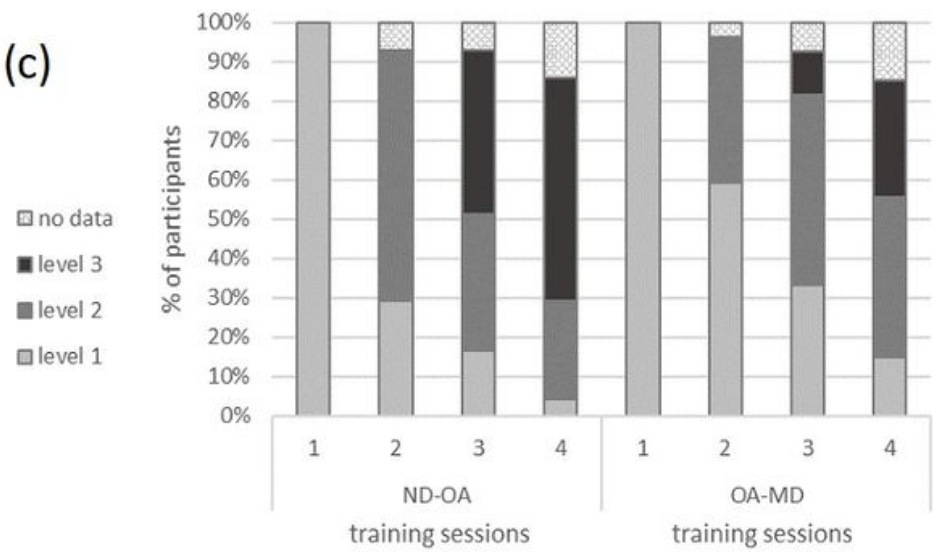

(d)

$\square$ no data

=level 3

- level 2

口 level 1

Figure 2

Percentage of participants from the groups of non-demented older adults and older adults with mild dementia who achieved particular levels of difficulty in subsequent training sessions in the following game modules: (a) memory; (b) attention; (c) visuospatial processing; (d) language Note: OA-ND - Nondemented older adults OA-MD - Older adults with mild dementia level 1, level 2, level 3 - levels of difficulty (from the easiest one to the most difficult) no data - the lack of data is the result of the problems 
with transferring data from the software to the database, which occurred a few times training sessions: 1 , 2, 3, 4 - subsequent training sessions in the intervention procedure 